\title{
Positive GBS Risk Status
}

National Cancer Institute

\section{Source}

National Cancer Institute. Positive GBS Risk Status. NCI Thesaurus. Code C111947.

Rectal/vag inal culture positive for group B Streptococcus (GBS) within 5 weeks. 